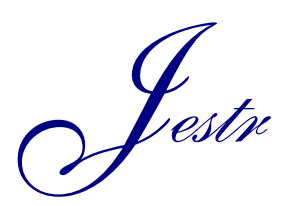

\title{
Experimental Study on Deformation Performance of Basalt Fiber-Reinforced Recycled Aggregate Concrete
}

\author{
Zhang Xianggang ${ }^{1,2, *}$, Yang Junna ${ }^{1}$, Wang Fang ${ }^{3}$ and Yang Jianhui ${ }^{1,2}$ \\ ${ }^{1}$ School of Civil Engineering, Henan Polytechnic University, Jiaozuo 454003, China \\ ${ }^{2}$ Henan Province Engineering Laboratory of Eco-architecture and the Built Environment, \\ Henan Polytechnic University, Jiaozuo 454000, China \\ ${ }^{3}$ Construction Decoration Co.Ltd of China Construction No.7 Engineering Bureau, Zhengzhou 450001, China
}

Received 10 August 2018; Accepted 25 September 2018

\begin{abstract}
To explore the basic deformation performance of basalt fiber-reinforced recycled aggregate concrete (BFRRC), a deformation experiment was conducted on fifteen groups of cubic standard specimens and fifteen groups of prismatic standard specimens. The destruction process and failure mode of the test blocks were observed. The elastic modulus and Poisson's ratio of the test blocks were tested, and then the stress-strain curve under compression was obtained. The influence of the replacement ratio of recycled coarse aggregate and the basalt fiber content on the stress-strain curve, elastic modulus and Poisson's ratio were analyzed, and then the functional expression of the rising section of the stressstrain curve and the theoretical calculation formula of the elastic modulus were established considering the replacement ratio of the recycled coarse aggregate and the basalt fiber content. It is shown that the compressive failure mode of BFRRC is similar to that of ordinary concrete. It was found that the calculated results of stress-strain rising section and elastic modulus of BFRRC were in good agreement with the measured ones. The elastic modulus of BFRRC decreased with the increase of the replacement ratio of recycled coarse aggregate and increased with the increase of fiber content, while the Poisson's ratio was the opposite.
\end{abstract}

Keywords: BFRRC, Failure mode, Replacement ratio of recycled coarse aggregate, Deformation performance

\section{Introduction}

The booming construction industry will also generate a lot of construction waste, especially waste concrete [1-2]. Due to the lack of proper treatment of abandoned concrete, abandoned concrete occupies a large amount of land resources and brings many problems to the environment [34]. Therefore, the rational recovery and recycling of waste concrete can, on the one hand, relieve the pressure of the growing scarcity of natural resources and, on the other hand, promote the sustainable development of the construction industry [5-6].

Recycled aggregate is formed by crushing, classifying, and other processes. Some or all of them replace natural aggregate, such as sand and stone, and then water, cement and other cementing materials are added to form concrete. That is recycled aggregate concrete (RAC) [7-8]. Basalt fiber (BF) is added to the recycled concrete to form Basalt Fiber-reinforced recycled aggregate concrete (BFRRC). BF has a good compatibility with concrete for toughening and cracking resistance of ordinary concrete, and it is regarded as a new type of green inorganic non-metallic material for sustainable development in the 21 st century [9-12]. Due to the internal cracks and porosity of recycled aggregate, poor particle gradation and so on, the basic properties of recycled aggregate are different from that of natural aggregate [13-

\footnotetext{
E-mail address: xgzhang1986@126.com

ISSN: $1791-2377$ @ 2018 Eastern Macedonia and Thrace Institute of Technology. All rights reserved. doi:10.25103/iestr.114.18
}

14]. Through the composite reinforcement of $\mathrm{BF}$, the mechanical performance of recycled concrete can be improved, and the extent of recycling of waste concrete will be promoted.

\section{State of the art}

As a new engineering material with application prospect, it is urgent to study the mechanical properties of BFRRC, especially the deformation properties. However, there are not many related literature reports at present. The research and application of BFRRC is still in its infancy. However, BFRRC was proposed and developed on the basis of RAC, and there were a large number of studies and reports on RAC uniaxial/tri-axial static performance and long-term performance. Within a certain range, RAC has also been realized in the application and development of a pilot project.

For the uniaxial static compression performance of RAC, Li et al. designed 33 RAC prismatic blocks, and the elastic modulus and Poisson's ratio tests were conducted. The results show that the brittleness of RAC is relatively obvious with the replacement ratio of recycled aggregate. Both axial compressive strength and elastic modulus are greater than the regeneration of standard age and ordinary concrete, but Poisson's ratio does not change significantly [15]. Chen et al. studied the uniaxial compressive strength, elastic modulus and Poisson's ratio of the RAC prismatic blocks and put forward the stress-strain constitutive equation of the recycled concrete [16]. Sun et al. studied the compressive strength 
and elastic modulus of RAC at different replacement ratios and ages and found that with the development of age, the strength development law of RAC is similar to that of general concrete. With the increase of the replacement ratio of recycled aggregate, the strength and elastic modulus of recycled aggregate concrete show the trend of decline [17]. Tabsh et al. carried out tests of mechanical properties with recycled coarse aggregate source and target concrete strength as variable parameters. The results show that the compressive and splitting tensile strength of RAC depends on the mix proportions [18]. Noguchi et al. used statistical data from 1,300 tests conducted in Japan and South Korea from 1980 to 2012 to analyze the relationship between compressive strength and elastic modulus [19]. In the triaxial static compression performance of RAC, Chen et al. found that the aging time and the lateral constraint have great influence on the peak strain and the elastic modulus of the RAC [20]. The above research basically shows that RAC is the main factor that deteriorates the mechanical properties of RAC. With the increase of the replacement ratio of RAC, the strength and elastic modulus of RAC decrease gradually. In the long-term performance of RAC, Tam et al. found that the drying shrinkage and creep behavior increased with the increase of the replacement ratio of RAC. Similar to mechanical properties, RAC also degrades the long-term performance of RAC [21].

Therefore, in order to improve the mechanical and longterm properties of RAC, many scholars have incorporated BF into RAC to modify them. Dong et al. found that the microstructure of the interface transition zone could be improved by the adhesion of coarse aggregate to the surface of mortar and the pore position of BF, which would improve the strength and ductility of RAC [22]. Katkhuda et al. found that using chopped BF can improve the compressive strength of RAC and can significantly improve the bending and splitting tensile strength [23]. Yang showed that adding an appropriate amount of BF to recycled concrete can improve the compressive strength and flexural strength and greatly improve the crack resistance of RAC [24]. Hou et al. discussed the influence of fiber content on the performance of RAC at different replacement ratios, and the research showed that $\mathrm{BF}$ has a better enhancement effect on RAC than ordinary concrete [25]. Fan et al. used a split Hopkinson pressure bar device to carry out impact tests on four kinds of basalt fiber reinforced concrete volume content and found that basalt fiber reinforced concrete has favorable impact mechanical properties, BF volume content has large effects on impact compressive strength and toughness of basalt fiber reinforced concrete [26]. Alnhhal et al. carried out flexural behavior tests of 16 reinforced BFRRC beams and found that the flexural capacity of recycled concrete beams doped with BF was improved [27]. Meng and Liu et al. studied the bond-slip stress-strain curves between BFRP bar and BFRRC. The results show that adding basalt fiber to RAC can reduce the bond stress between BFRP bar and RAC but enhance the ductility of bond property. At the same time, the bond stress increases with the increase of BF length and RAC grade [28-29]. The above studies mainly focus on the improvement of the strength of RAC by $\mathrm{BF}$, and the conclusions are basically consistent. After the incorporation of $\mathrm{BF}$, the compressive strength of RAC, especially the mechanical properties of bending strength, splitting tensile strength and impact strength can be obviously improved. However, there are few studies on static compression deformation performance.

In view of the previous research insufficiency, the recycled coarse aggregate replacement ratio and the content of $\mathrm{BF}$ were used as parameters to prepare BFRRC, and the deformation performance was tested systematically. First, the destruction process and failure mode of BFRRC are analyzed, and then the relationship between BFRRC stressstrain curve, elastic modulus and Poisson's ratio are discussed. The purpose is to provide reference for further research and engineering application of BFRRC.

The rest of this study is arranged as follows. Section 3 describes the test design. In Section 4, the stress-strain curve, elastic modulus and Poisson's ratios of BFRRC are quantitatively analyzed. Section 5 summarizes this article and gives the relevant conclusions.

\section{Materials and methods}

\subsection{Materials}

The cement used in this experiment is $\mathrm{P} \cdot \mathrm{O} 42.5 \mathrm{R}$ grade cement produced by a cement plant in Jiaozuo. The natural coarse aggregate was made of continuously graded crushed stone. The regenerated coarse aggregate was obtained by manual crushing, screening, cleaning and drying of reinforced concrete beams tested in the structural hall of a university in Henan. Natural yellow sand was selected as fine aggregate. Its bulk density is $1750 \mathrm{~kg} / \mathrm{m}^{3}$, and its apparent density is $2300 \mathrm{~kg} / \mathrm{m}^{3}$. The mixing water is common tap water. The basic physical properties of natural coarse aggregate and recycled concrete are presented in Table 1. The basic performance of BF is presented in Table 2.

Table 1. Basic physical properties of coarse aggregate

\begin{tabular}{c|c|c|c|c|c}
\hline $\begin{array}{c}\text { Type of coarse } \\
\text { aggregate }\end{array}$ & $\begin{array}{c}\text { Size } \\
(\mathbf{m m})\end{array}$ & $\begin{array}{c}\text { Bulk density } \\
\left(\mathrm{kg} / \mathrm{m}^{3}\right)\end{array}$ & $\begin{array}{c}\text { Apparent density } \\
\left(\mathrm{kg} / \mathrm{m}^{3}\right)\end{array}$ & Moisture content $\mathbf{( \% )}$ & $\begin{array}{c}\text { Water absorption } \\
(\%)\end{array}$ \\
\hline Natural aggregate & $5-31.5$ & 1681 & 2498 & 0 & 0.1 \\
Recycled aggregate & $5-31.5$ & 1274 & 2196 & 2 & 5.6 \\
\hline
\end{tabular}

Table 2. Properties of basalt fiber

\begin{tabular}{c|c|c|c|c|c}
\hline Diameter ( m) & Length (mm) & $\begin{array}{c}\text { Density } \\
\left(\mathrm{kg} / \mathrm{m}^{3}\right)\end{array}$ & $\begin{array}{c}\text { Tensile strength } \\
(\mathbf{M P a})\end{array}$ & $\begin{array}{c}\text { Elastic modulus } \\
(\mathbf{G P a})\end{array}$ & $\begin{array}{c}\text { Elongation at break } \\
\mathbf{( \% )}\end{array}$ \\
\hline 15 & 18 & 2650 & $4150-4850$ & $93-115$ & $3.0-3.2$ \\
\hline
\end{tabular}

\subsection{Design of mixture proportions}

Five kinds $(0 \%, 25 \%, 50 \%, 75 \%, 100 \%)$ of recycled coarse aggregate replacement ratio $\delta$ were designed, and three kinds of BF content $\left(0 \mathrm{~kg} / \mathrm{m}^{3}, 2 \mathrm{~kg} / \mathrm{m}^{3}\right.$ and $\left.4 \mathrm{~kg} / \mathrm{m}^{3}\right)$ were used. The replacement ratio was designed according to the mass percentage of recycled concrete in total coarse aggregate. The replacement ratio of $0 \%$ and the BF content of $0 \mathrm{~kg} / \mathrm{m}^{3}$ were used as the reference test blocks. The test strength grade was $\mathrm{C} 35$, and the remaining test blocks were 
used as contrast test blocks. The fly ash was grade II fly ash produced by a power plant in Gongyi City. The dosage was $20 \%$ of the amount of cement, and the dosage of the water reducing agent was $0.5 \%$ of the cementitious materials. The mixture proportions used in the test is shown in Table 3 . The measured BFRRC slump is within the range of $150-180 \mathrm{~mm}$.

Table 3. Mixture proportions of recycled aggregate concrete $\left(\mathrm{kg} / \mathrm{m}^{3}\right)$

\begin{tabular}{|c|c|c|c|c|c|c|c|c|c|c|}
\hline$\delta(\%)$ & $\boldsymbol{W} / \boldsymbol{B}$ & $\begin{array}{c}\text { Sand ratio } \\
(\%)\end{array}$ & $\begin{array}{c}\text { Net water } \\
\text { consumption }\end{array}$ & $\begin{array}{l}\text { Additional } \\
\text { water }\end{array}$ & Cement & Fly ash & $\begin{array}{c}\text { Recycled coarse } \\
\text { aggregate }\end{array}$ & $\begin{array}{c}\text { Natural coarse } \\
\text { aggregate }\end{array}$ & Sand & $\begin{array}{c}\text { Water- } \\
\text { reducing } \\
\text { agent }\end{array}$ \\
\hline 0 & 0.4 & $31 \%$ & 205.0 & 0.0 & 427.1 & 85.4 & 0.0 & 1115.2 & 501.0 & 2.56 \\
\hline 25 & 0.4 & $31 \%$ & 205.0 & 15.6 & 427.1 & 85.4 & 278.8 & 836.4 & 501.0 & 2.56 \\
\hline 50 & 0.4 & $31 \%$ & 205.0 & 31.2 & 427.1 & 85.4 & 557.6 & 557.6 & 501.0 & 2.56 \\
\hline 75 & 0.4 & $31 \%$ & 205.0 & 46.8 & 427.1 & 85.4 & 836.4 & 278.8 & 501.0 & 2.56 \\
\hline 100 & 0.4 & $31 \%$ & 205.0 & 62.5 & 427.1 & 85.4 & 1115.2 & 0.0 & 501.0 & 2.56 \\
\hline
\end{tabular}

\subsection{Test block formation and loading method}

In order to study the effect of single influence parameters on the deformation behavior of basalt recycled concrete, 15 groups of three $150 \mathrm{~mm} \times 150 \mathrm{~mm} \times 150 \mathrm{~mm}$ cubes were designed for measuring the compressive strength of the cubes. Fifteen groups of standard prismatic blocks of three groups of $150 \mathrm{~mm} \times 150 \mathrm{~mm} \times 300 \mathrm{~mm}$ were designed to carry out axial compressive stress-strain whole process tests. Three other prismatic block test pieces were tested for elastic modulus and Poisson's ratio.

The formation and maintenance of BFRRC was carried out according to "Standard Test Method for Performance of Normal Concrete Mixture" (GB/T 50080-2002).

The test was carried out using a microcomputercontrolled electrohydraulic servo pressure tester (WAW1000 model) manufactured by Changchun New Test Machine Co., Ltd. The maximum test force was $1000 \mathrm{kN}$.

\section{Result analysis}

\subsection{Failure process and failure mode}

The classic failure modes of test blocks are shown in Figs. 1 and 2. At the beginning of loading, there was no visible change on the surface of the cube. With the increase of load, the stress inside the test blocks increased gradually, and occasionally there was a weak sound of colloidal cracking. When the load was increased to the ultimate load, one or several cracks and micro cracks occurred in the middle of the test blocks, and then the crack and micro crack developed rapidly to the angle of upper and lower pressure surface, forming the main crack, gradually pushing the drum to the free surface and eventually forming a square pyramidal damage that was connected to it. It can be seen that the failure modes of BFRRC test blocks and ordinary concrete blocks are basically the same.

The classic failure modes of prismatic blocks are shown in Fig. 3. At the initial stage of loading, there was no visible change in the surface of the BFRRC prismatic blocks. With the increase of the load, the stress on the test block increased gradually. Occasionally, there was a slight "click" sound of colloidal cracking when the load continued to increase. There were some tiny micro cracks on the surface of the test blocks along the direction of force loading, and they expanded and penetrated as the load continued to increase. When the load approached ultimate load, large area block flaking and brittle failure appeared in the prismatic test blocks.

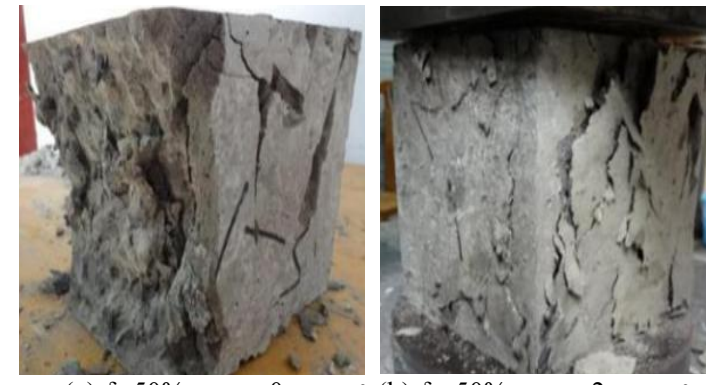

(a) $\delta=50 \% \quad m_{\mathrm{BF}}=0 \mathrm{~kg} / \mathrm{m}^{3}$ (b) $\delta=50 \% m_{\mathrm{BF}}=2 \mathrm{~kg} / \mathrm{m}^{3}$

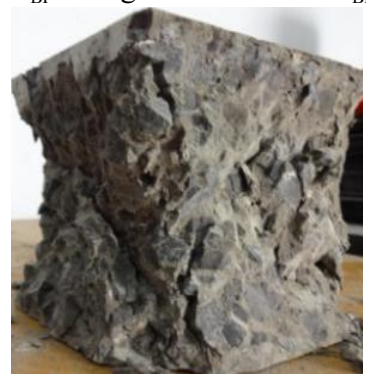

(c) $\delta=50 \% m_{\mathrm{BF}}=4 \mathrm{~kg} / \mathrm{m}^{3}$

Fig. 1. Classic failure modes of test blocks with the same replacement ratio

\subsection{Stress-strain curve}

According to the load and strain data of BFRRC prismatic blocks measured by experiment, the stress of the specimens in the axial compression process is obtained by using formula (1), and the strain is measured by strain gauge. Because the descending section curves measured by strain gauges are discrete and partial descending section curves are incomplete, this paper only analyzes the rising section of the curve. As shown in Fig. 4, the rising section curve is taken from the average of three prismatic curves.

$\sigma=N / A$

where $N$ is the axial pressure of the specimens and $A$ is the cross-sectional area of the specimens.
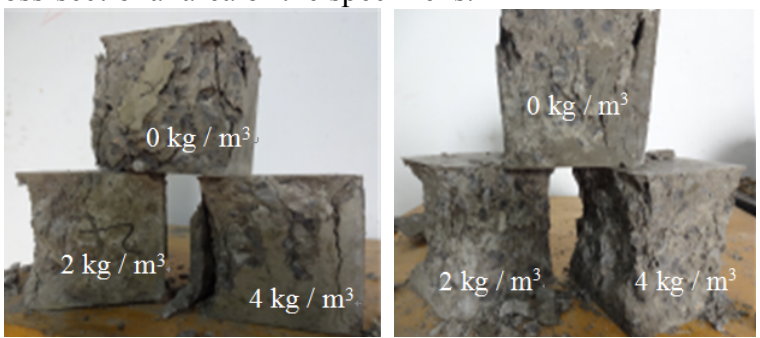

(a) $\delta=0 \%$

(b) $\delta=50 \%$ 


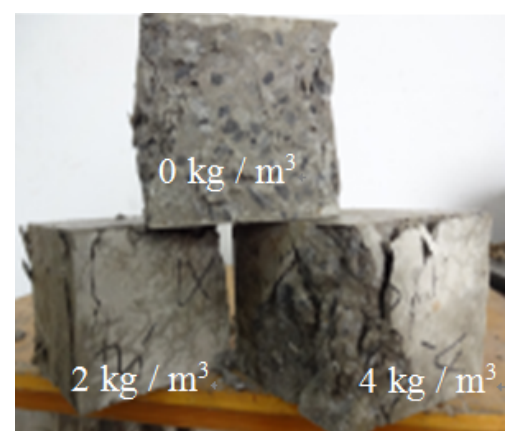

(c) $\delta=75 \%$

Fig. 2. Classic failure modes of test blocks with different replacement ratio and $0-4 \mathrm{~kg} / \mathrm{m}^{3}$ of $m_{\mathrm{BF}}$

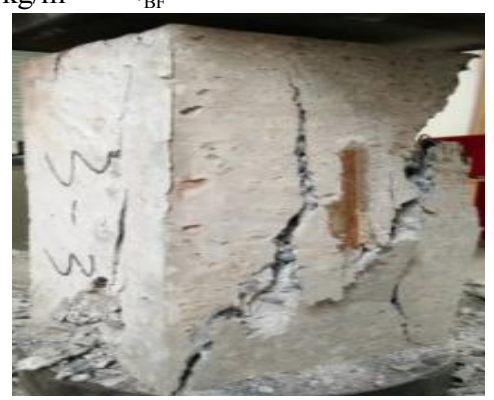

Fig. 3. Classic failure modes of test blocks with $50 \%$ of $\delta$ and 4 $\mathrm{kg} / \mathrm{m}^{3}$ of $m_{\mathrm{BF}}$

It is shown in Fig. 4 that, under the same BF content, the replacement ratio has a great influence on the stress-strain curve of BFRRC, but all have a similar uplift and the slope is smaller than that of ordinary concrete. It shows that the elastic modulus of BFRRC is lower than that of ordinary concrete. According to the measured stress-strain curves of BFRRC, $\varepsilon_{\mathrm{c}}$ dimensionless analysis was carried out. $\sigma_{\mathrm{c}}$ represents the peak strain, $c$ represents the peak stress, and the dimensionless stress-strain curve is shown in Fig. 5.

As shown in Fig. 5, the rising section of BFRRC is similar to the rising section of ordinary concrete. Using the constitutive model proposed in "Code for Design of Concrete Structures" (GB/T 50010-2010), the rising section of the curve is analyzed, as shown in formula (2).

$$
y=a x+(3-2 a) x^{2}+(a-2) x^{2} \quad 0 \leq x<1
$$

Based on the fitting analysis of the data obtained from the test, the principle of the method of least squares is used to calculate the values of the undetermined parameters $a$ under different $\mathrm{BF}$ content and the replacement ratio of recycled concrete. Table 4 shows that the corresponding fitting accuracy is above 0.95 .

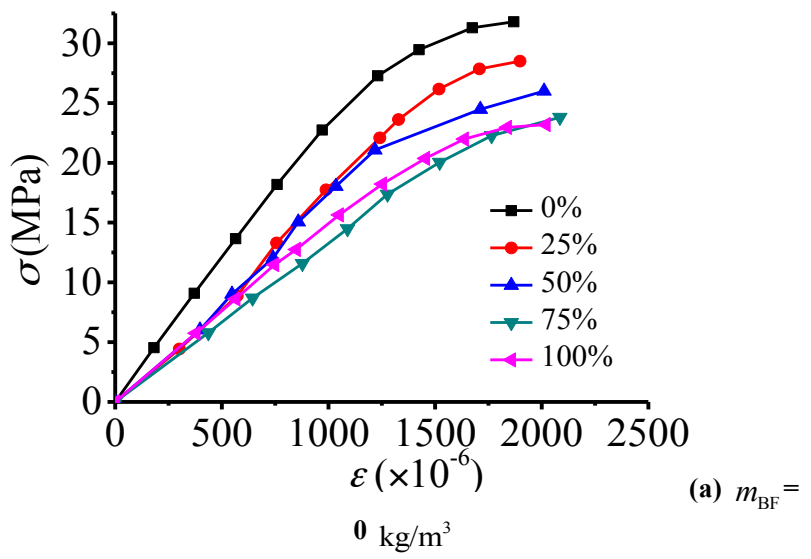

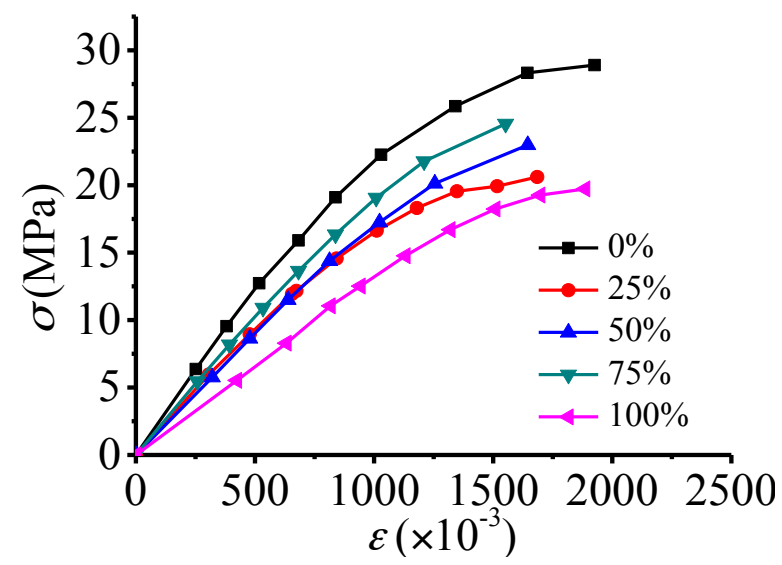

(b) $m_{\mathrm{BF}}=2 \mathrm{~kg} / \mathrm{m}^{3}$

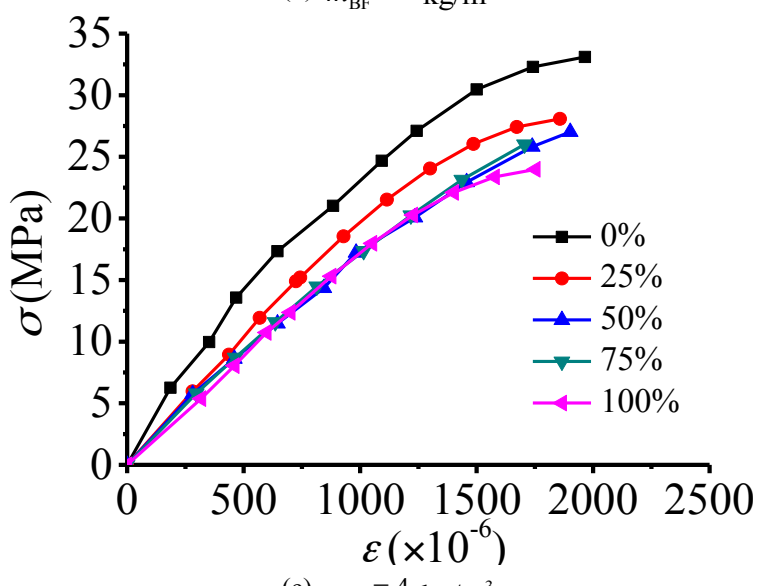

(c) $m_{\mathrm{BF}}=4 \mathrm{~kg} / \mathrm{m}^{3}$

Fig. 4. Stress-strain rising section curve of BFRRC

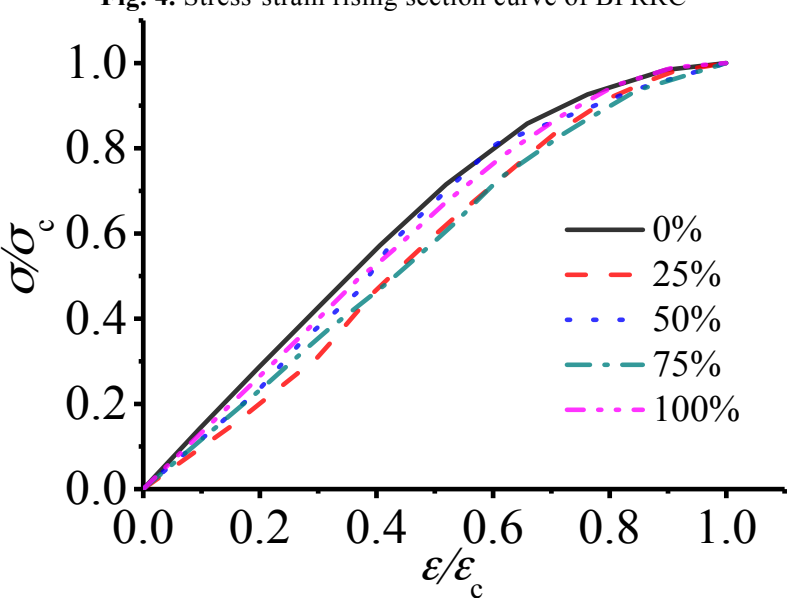

(a) $m_{\mathrm{BF}}=\mathbf{0} \mathrm{kg} / \mathrm{m}^{3}$

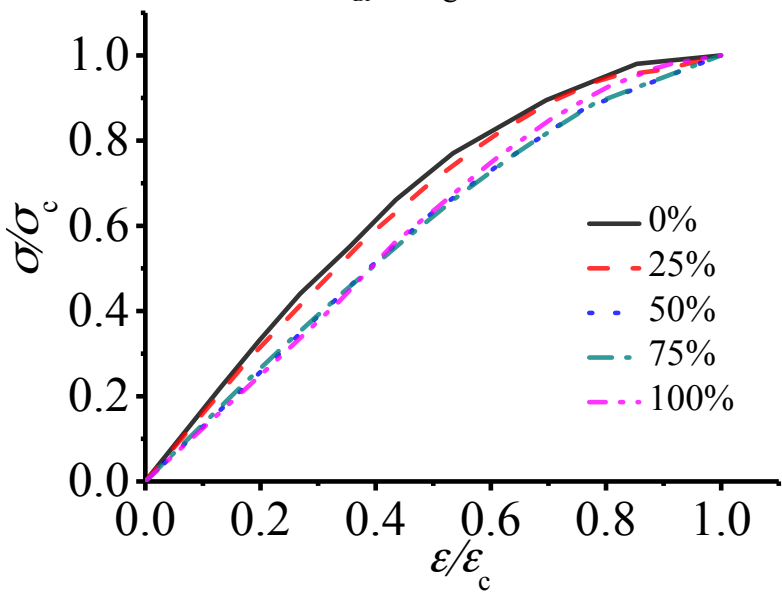

(b) $m_{\mathrm{BF}}=2 \mathrm{~kg} / \mathrm{m}^{3}$ 


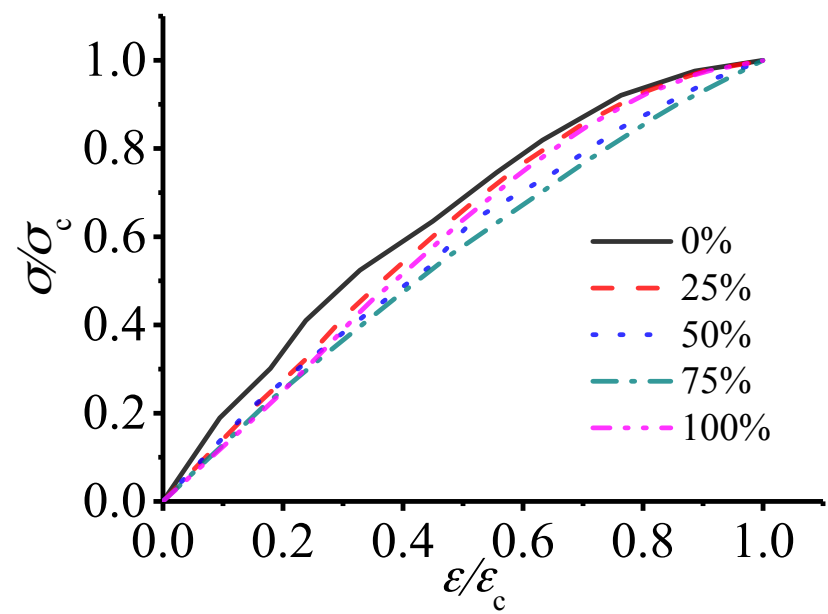

(c) $m_{\mathrm{BF}}=4_{\mathrm{kg} / \mathrm{m}^{3}}$

Fig. 5. Dimensionless stress-strain rising section curve of BFRRC

Table 4. The parameters a of different basalt fiber content and different replacement ratio

\begin{tabular}{c|c|c|c|c|c}
\hline \multirow{2}{*}{$\begin{array}{c}m_{\mathrm{BF}}( \\
\left.\mathrm{kg} / \mathrm{m}^{3}\right)\end{array}$} & 0 & 25 & 50 & 75 & 100 \\
\cline { 2 - 6 } & 1.48 & 0.76 & 0.34 & 0.65 & 1.19 \\
2 & 1.81 & 1.54 & 1.10 & 1.10 & 0.98 \\
4 & 1.74 & 1.27 & 0.99 & 0.81 & 1.11 \\
\hline
\end{tabular}

By statistical analysis, the relationship between the parameters $a$ and the replacement ratio of regenerated coarse aggregate under different $\mathrm{BF}$ content is obtained by regression, as shown in formulas (3), (4), and (5).

When $m_{\mathrm{BF}}=0 \mathrm{~kg} / \mathrm{m}^{3}$,

$a=3.69 \delta^{2}-3.96 \delta+1.477,0 \leq \delta<1 \quad R^{2}=0.9677$

When $m_{\mathrm{BF}}=2 \mathrm{~kg} / \mathrm{m}^{3}$,

$a=0.846 \delta^{2}-1.686 \delta+1.832,0 \leq \delta<1 \quad R^{2}=0.9208$

When $m_{\mathrm{BF}}=4 \mathrm{~kg} / \mathrm{m}^{3}$,

$a=1.87 \delta^{2}-2.56 \delta+1.762,0 \leq \delta<1 \quad R^{2}=0.9537$

Considering the simple and practical requirement of the fitting relation, the modified equation $\psi, \psi=e \lambda^{2}+c \lambda+d$ for $\mathrm{BF}$ content is introduced, where $\lambda$ is the BF admixture quantity and $e, c$ and $d$ are the control parameters. The mathematical expressions of the three fibers were fitted again, and the functional expressions of parameter $a$ and replacement ratio and BF content were obtained, as shown in formula (6).

$$
\begin{aligned}
a= & \left(0.484 \lambda^{2}-2.39 \lambda+3.69\right) \delta^{2}+\left(-0.395 \lambda^{2}+1.93 \lambda-3.96\right) \delta \\
& +\left(-0.05 \lambda^{2}+0.284 \lambda+1.477\right) \quad R^{2}=1
\end{aligned}
$$

Taking $\delta=25 \%$ and $\delta=100 \%$ as examples, the values of $a$ are calculated by using formula (6), and then the axial stressstrain curves of BFRRC are calculated and compared with the measured curves. As shown in Figs. 6 and 7, the two are in good agreement.
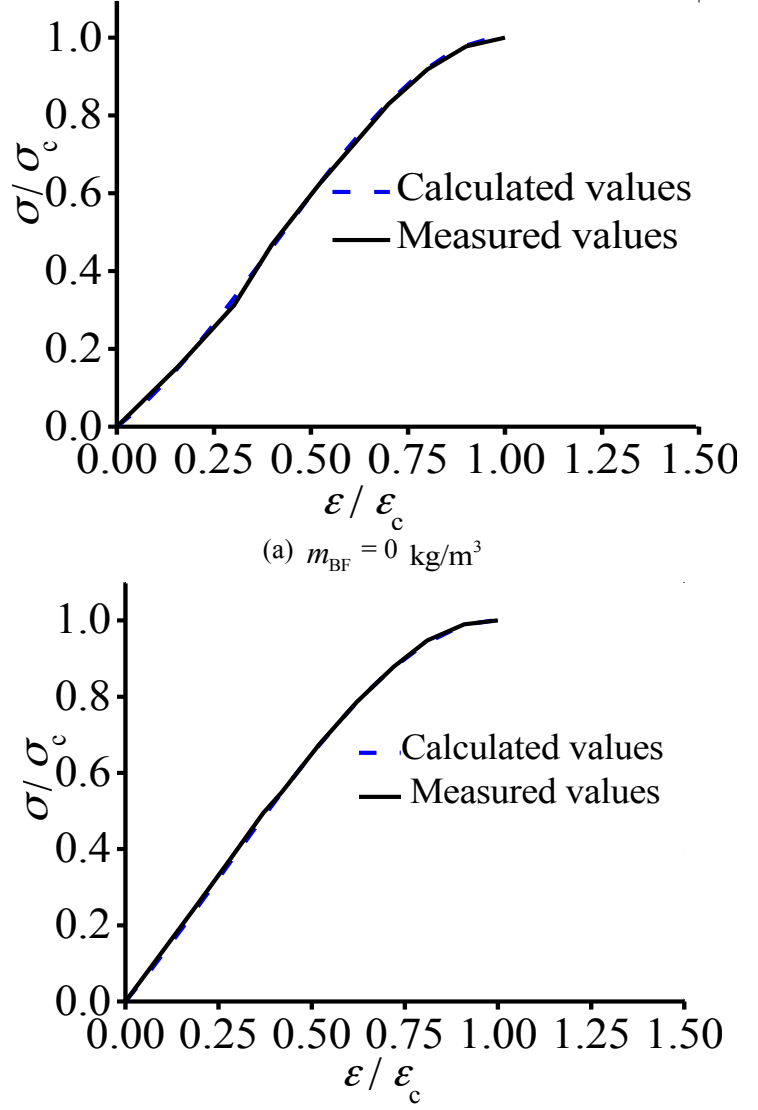

(b) $m_{\mathrm{BF}}=2 \mathrm{~kg} / \mathrm{m}^{3}$

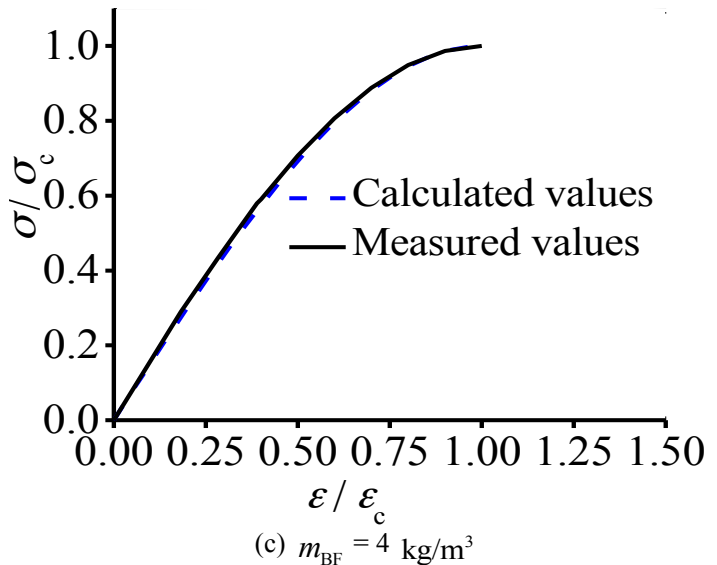

Fig. 6. Comparison of test and calculated stress-strain curve under the same $\delta$ of $25 \%$

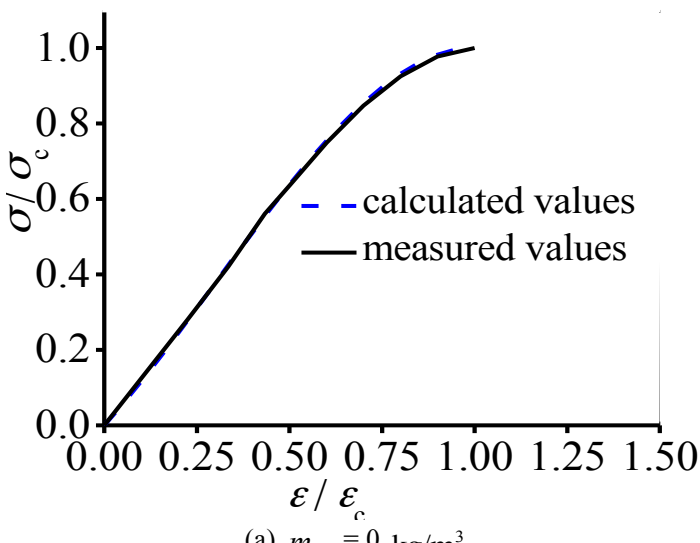

(a) $m_{\mathrm{BF}}=0 \mathrm{~kg} / \mathrm{m}^{3}$ 

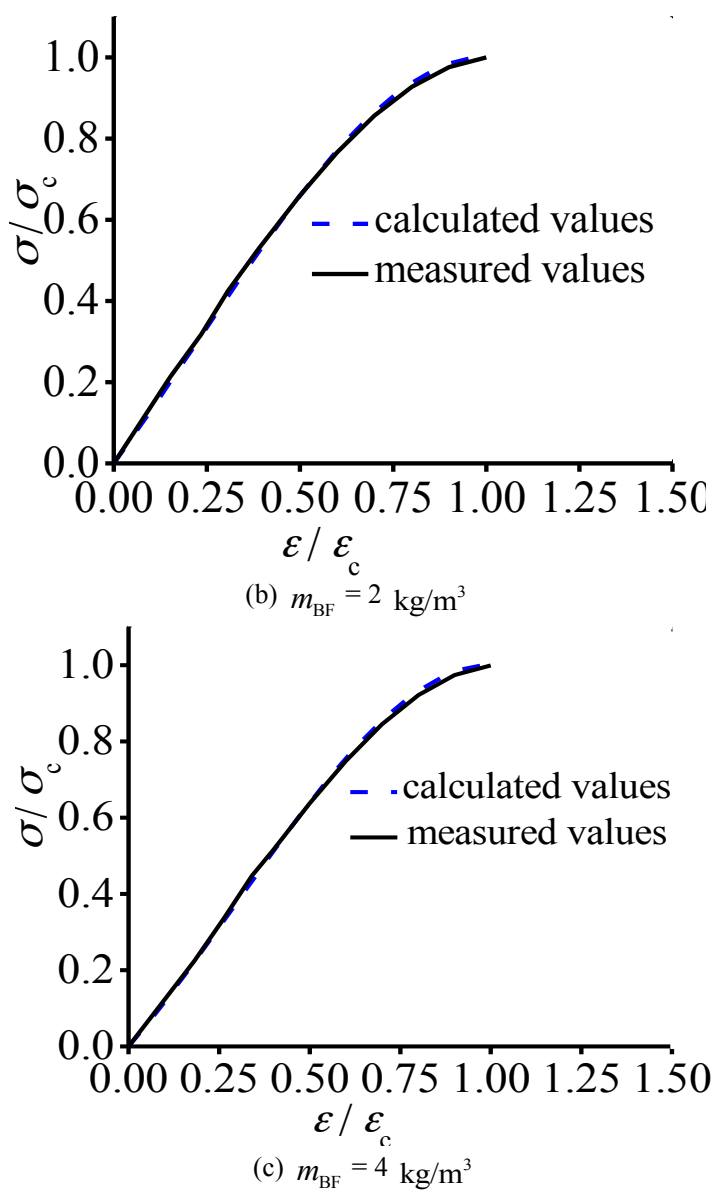

Fig. 7. Comparison of test and calculated stress-strain curve under the same $\delta$ of $100 \%$

\subsection{Elastic modulus}

As one of the important indicators of material deformation performance, many scholars have conducted a large number of experimental studies on the elastic modulus of RAC and achieved certain results [30-31]. However, there are few reports about the mathematical expression of elastic modulus of BFRRC. According to "Code for Design of Concrete Structures" (GB/T 50010-2010), the equation for calculating the elastic modulus of ordinary concrete is shown in formula (7).

$$
E_{\mathrm{c}}=\frac{10^{5}}{2.2+\frac{34.7}{f_{\mathrm{cu}}}}
$$

The measured compressive strength of the cube is substituted into equation (7) to obtain the calculated value $E_{\mathrm{c}}^{\mathrm{c}}$ of BFRRC, and the secant modulus from origin to $0.4 f_{\mathrm{c}}$ on the stress-strain curve was taken as the elastic modulus measured by BFRRC $E_{\mathrm{c}}^{\mathrm{t}}$. The calculated values and test values of elastic modulus of BFRRC are shown in Table 5 .

It can be seen from Table 5 that with the increase of replacement ratio, the elastic modulus of BFRRC as a whole shows a decreasing rule, so the increase of regenerated coarse aggregate makes the initial damage of BFRRC serious and the porosity increases. At the same replacement ratio, the elastic modulus of BFRRC increases with the increase of $\mathrm{BF}$ content, especially when the replacement ratio is $0 \%$ and the $\mathrm{BF}$ content is $4 \mathrm{~kg} / \mathrm{m}^{3}$ where the elastic modulus reaches the maximum, which indicates that $\mathrm{BF}$ inhibits the development of cracks and micro cracks to some extent. The overall elastic modulus of BFRRC shows a decreasing rule.

Table. 5. The calculated values and measured values of elastic modulus for BFRRC

\begin{tabular}{c|c|c|c}
\hline$\delta(\%)$ & $m_{\mathrm{BF}}\left(\mathrm{kg} / \mathrm{m}^{3}\right)$ & $E_{\mathrm{c}}{ }^{\mathrm{c}}(\mathrm{GPa})$ & $E_{\mathrm{c}}{ }^{\mathrm{t}}(\mathrm{GPa})$ \\
\hline 0 & 0 & 31.97 & 24.70 \\
25 & 0 & 31.74 & 16.80 \\
50 & 0 & 31.12 & 16.60 \\
75 & 0 & 30.73 & 13.30 \\
100 & 0 & 30.66 & 15.20 \\
0 & 2 & 32.10 & 24.80 \\
25 & 2 & 31.87 & 19.01 \\
50 & 2 & 31.31 & 18.48 \\
75 & 2 & 30.99 & 14.60 \\
100 & 2 & 30.79 & 13.42 \\
0 & 4 & 32.29 & 28.40 \\
25 & 4 & 32.02 & 21.47 \\
50 & 4 & 31.66 & 18.91 \\
75 & 4 & 31.36 & 19.06 \\
100 & 4 & 31.11 & 18.27 \\
\hline
\end{tabular}

The relationship between $E_{\mathrm{c}}^{\mathrm{t}} / E_{\mathrm{c}}^{\mathrm{c}}$ and replacement ratio is shown in Fig. 8 at different BF content. It can be seen that the calculated by mathematical expression (7) is greater than, and the current specification is no longer applicable to the calculation of BFRRC elastic modulus. Therefore, take polynomial to modify formula (7), according to the $E_{\mathrm{c}}^{\mathrm{t}} / E_{\mathrm{c}}^{\mathrm{c}}$ and the change trend of relation curve, when the BF content is $0 \%$ the expression is shown in the formula (8), and the expression of the other BF content is shown in the formula (9).

$$
\begin{aligned}
& E_{\mathrm{c}}=\frac{10^{5}}{2.2+\frac{34.7}{f_{\text {cu }}}}(A \delta+B \delta+C) \\
& E_{\mathrm{c}}=\frac{10^{5}}{2.2+\frac{34.7}{f_{\text {cu }}}}(D \delta+E \delta+F \delta+G)
\end{aligned}
$$

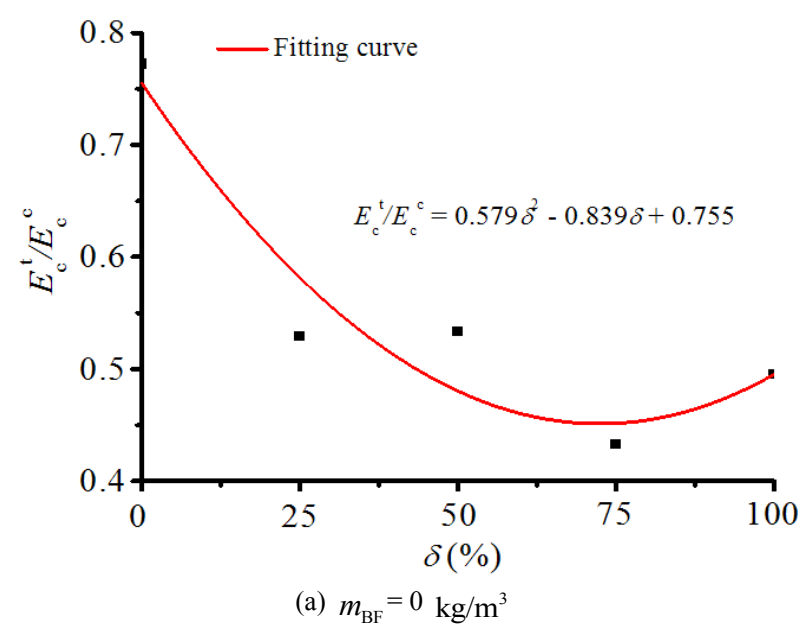

Among them, $A, B, C, D, E, F, G$ are control parameters, and the parameter values are obtained by using the least squares principle. When the content of $\mathrm{BF}$ is $0 \%, 2 \%$ and $4 \%$, the elastic modulus are calculated by formula (10), (11) and (12), respectively. 


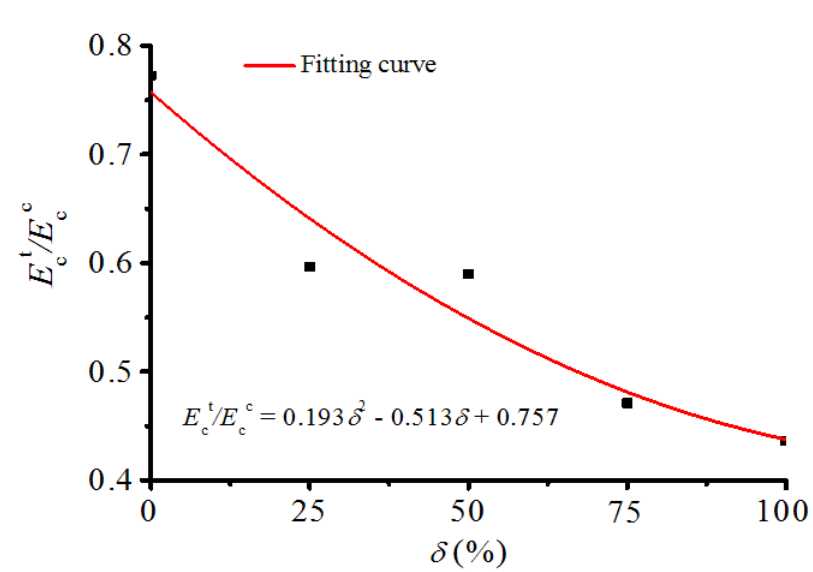

(b) $m_{\mathrm{BF}}=2 \mathrm{~kg} / \mathrm{m}^{3}$

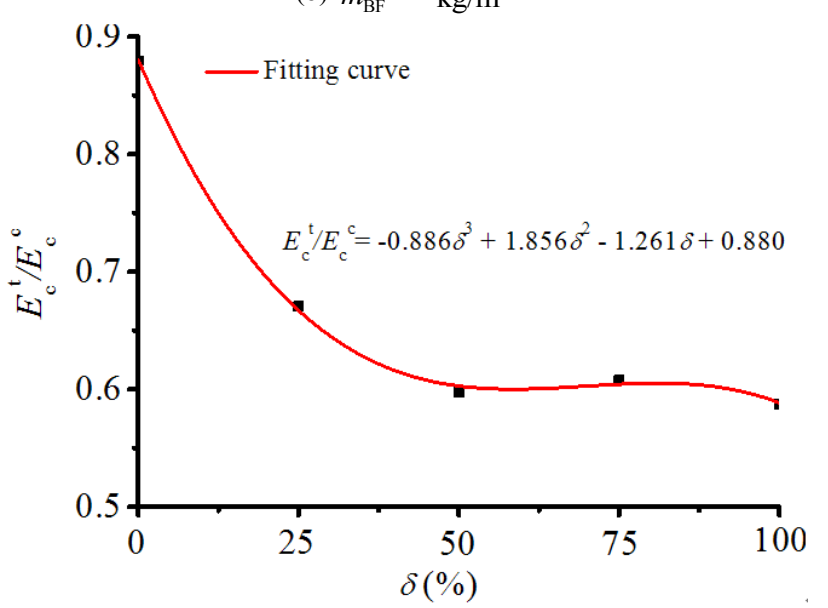

(c) $m_{\mathrm{BF}}=4 \mathrm{~kg} / \mathrm{m}^{3}$

Fig. 8. Relationship curves of $E_{\mathrm{c}}^{\mathrm{t}} / E_{\mathrm{c}}^{\mathrm{c}}$ versus $\delta$

$$
\begin{aligned}
& E_{\mathrm{c}}=\frac{10^{5}}{2.2+\frac{34.7}{f_{\mathrm{cu}}}}\left(0.579 \delta^{2}-0.838 \delta+0.755\right) \\
& R^{2}=0.814 . \\
& E_{\mathrm{c}}=\frac{10^{5}}{2.2+\frac{34.7}{f_{\text {cu }}}}\left(0.193 \delta^{2}-0.153 \delta+0.757\right)
\end{aligned}
$$

$R^{2}=0.8666$

$$
\begin{aligned}
& E_{\mathrm{c}}=\frac{10^{5}}{2.2+\frac{34.7}{f_{\mathrm{cu}}}}\left(-0.886 \delta^{2}+1.856 \delta-1.261 \delta+0.88\right) \\
& R^{2}=0.9964 .
\end{aligned}
$$

\subsection{Poisson's ratio}

The lateral strain and longitudinal strain data of the test blocks were collected by the strain gauge and are calculated by equation (13) to obtain the Poisson's ratio of BFRRC. See Table 6, where $\varepsilon$ is lateral strain and $\varepsilon^{\prime}$ is longitudinal strain.

Table. 6. Poisson's ratios of BFRRC under different stress

\begin{tabular}{l|c|c|c|c|c}
\hline$\delta(\%)$ & $\begin{array}{c}m_{\mathrm{BF}} \\
\left(\mathrm{kg} / \mathrm{m}^{3}\right)\end{array}$ & $0.2 f_{\mathrm{c}}$ & $0.4 f_{\mathrm{c}}$ & $0.6 f_{\mathrm{c}}$ & $0.8 f_{\mathrm{c}}$ \\
\hline
\end{tabular}

\begin{tabular}{c|l|l|l|l|l}
\hline 0 & 0 & 0.16 & 0.20 & 0.24 & 0.28 \\
25 & 0 & 0.17 & 0.23 & 0.24 & 0.29 \\
50 & 0 & 0.17 & 0.25 & 0.26 & 0.30 \\
75 & 0 & 0.18 & 0.26 & 0.26 & 0.32 \\
100 & 0 & 0.22 & 0.27 & 0.28 & 0.34 \\
0 & 2 & 0.14 & 0.16 & 0.20 & 0.26 \\
25 & 2 & 0.16 & 0.17 & 0.22 & 0.27 \\
50 & 2 & 0.16 & 0.19 & 0.25 & 0.29 \\
75 & 2 & 0.17 & 0.20 & 0.25 & 0.31 \\
100 & 2 & 0.19 & 0.22 & 0.27 & 0.32 \\
0 & 4 & 0.12 & 0.14 & 0.19 & 0.24 \\
25 & 4 & 0.14 & 0.16 & 0.20 & 0.28 \\
50 & 4 & 0.15 & 0.18 & 0.24 & 0.30 \\
75 & 4 & 0.16 & 0.19 & 0.25 & 0.31 \\
100 & 4 & 0.18 & 0.21 & 0.26 & 0.32 \\
\hline
\end{tabular}

It can be seen from Table 6 that the Poisson's ratio of BFRRC increases gradually with the increase of stress, then at the same stress level, the transverse deformation of BFRRC becomes larger with the increase of load. With the same BF content, the Poisson's ratio of BFRRC showed a slight increase with the increase of the replacement ratio, so the increase of regenerated coarse aggregates would lead to the lateral deformation of the test blocks. At the same replacement ratio, the Poisson's ratio of BFRRC showed a small decrease with increasing fiber content, especially when the replacement ratio is $0 \%$ and the $\mathrm{BF}$ content is 4 $\mathrm{kg} / \mathrm{m}^{3}$ the Poisson's ratio reached a minimum. This indicates that to some extent the $\mathrm{BF}$ inhibits the transverse deformation of the specimen.

\section{Conclusions}

In this study, fifteen BFRRC cubic standard specimens and fifteen BFRRC prismatic standard specimens were carried out experiment and analysis for stress-strain curve, elastic modulus and Poisson's ratio. The main conclusions are listed as follows:

(1) The compressed BFRRC cube finally forms a fourangled conical failure form that is connected to each other, which is basically the same as that of a normal concrete cube.

(2) Non-dimensional analysis of the stress-strain curve of the BFRRC was carried out. The functional expression of the rising section of the replacement ratio of recycled coarse aggregate and the BF content is established, and the calculated curve of the stress-strain rising section is in good agreement with the measured curve.

(3) When the BF content is constant, the elastic modulus of BFRRC decreases with the increase of replacement ratio of recycled coarse aggregate. When the replacement ratio of recycled coarse aggregate is constant, the elastic modulus of BFRRC shows an increasing trend with the increase of BF content. The change of Poisson's ratio is contrary to the change of elastic modulus.

(4) The formula of the elastic modulus of ordinary concrete is modified by using the polynomial function form, and the formula of BFRRC elastic modulus is obtained. The calculated value is in good agreement with the measured value.

The strength grade of BFRRC mixture proportions selected is $\mathrm{C} 35$ in this paper, and the correlation expression of deformation performance is related to the strength grade. The BFRRC of other strength levels is applicable to this 
formula, which needs to be further verified by experiments and theoretical analysis.

\section{Acknowledgements}

This work was financially supported by the Science and Technology Breakthrough Project of Henan Province (172102210285), the Fundamental Research Funds for the Universities of Henan Province (NSFRF170921), the Safe
Production Project of Key Technology for Major Accident Prevention and Control (Henan-0006-2016AQ).

This is an Open Access article distributed under the terms of the Creative Commons Attribution License

\section{References}

1. Mcneil, K., Kang, T. H. K., "Recycled concrete aggregates: a review", International Journal of Concrete Structures and Materials, 7(1), 2013, pp. 61-69.

2. Aslani, F., Ma, G. W., Wan, D. L. Y., Muselin, G., "Development of high-performance self-compacting concrete using waste recycled concrete aggregates and rubber granules". Journal of Cleaner Production, 182, 2018, pp. 553-566.

3. Hossain, M. U., Wu, Z. Z., Poon, C. S., "Comparative environmental evaluation of construction waste management through different waste sorting systems in HongKong". Waste Management, 69, 2017, pp. 325-335.

4. Boz, A., Sezer, A., "Influence of fiber type and content on freezethaw resistance of fiber reinforced lime stabilized clay". Cold Regions Science and Technology, 151, 2018, pp. 359-366.

5. Levy, S. M., Helene, P., "Durability of recycled aggregates concrete: a safe way to sustainable development". Cement and Concrete Research, 34(11), 2004, pp. 1975-1980.

6. Dhir, R. K., Paine, K. A., "Value added sustainable use of recycled and secondary aggregates in concrete". Indian Concrete Journal, 84(3), 2010, pp. 7-26.

7. Pasandin, A. R., Perez, I., "Overview of bituminous mixtures made with recycled concrete aggregates". Construction and Building Materials, 74, 2015, pp. 151-161.

8. Pedro, D., de Brito, J., Evangelista, L., "Influence of the use of recycled concrete aggregates from different sources on structural concrete". Construction and Building Materials, 71, 2014, pp. 141151.

9. Zhang, X. G., Kuang, X. M., Yang, J. H.,Wang, S. R., "Experimental Study on mechanical properties of lightweight concrete with shale aggregate replaced partially by nature sand". Electronic Journal of Structural Engineering, 17(1), 2017, pp. 85-94.

10. Amuthakkannan, P., Manikandan, V., Uthayakumar, M., "Mechanical properties of basalt and glass fiber reinforced polymer hybrid composites". Journal of Advanced Microscopy Research, 9(1), 2014, pp. 44-49.

11. Wang, S. R., Xiao, H. G., Hagan, P., Zou, Z. S., "Mechanical behavior of fully-grouted bolt in jointed rocks subjected to double shear tests". DYNA, 92(3), 2017, pp.314-320.

12. Wang, S. R., Xiao, H. G., Cao, C., Zou, Z. S., Liu, X. L., "Simulation verification analysis of anchoring characteristics of transverse rib steel bar during pull-out test". DYNA, 91(5), 2016, pp 548-553.

13. Casuccio, M., Torrijos, M. C., Giaccio, G., Zerbino, R., "Failure mechanism of recycled aggregate concrete". Construction and Building Materials, 22(7), 2008, pp. 1500-1506.

14. Weimann, K., Giese, L. B., Mellmann, G., Simon, F. G., "Building materials from waste". Materials Transactions, 44(7), 2003, pp. 1255-1258.

15. Li, W. N., Zhan, D. H., Xu, J. J., Zhang, W., Chen, Z. P., "Test research on elastic modulus and Poisson's ratios of long age recycled aggregate concrete". Applied Mechanics and Materials, 174-177, 2012, pp. 1051-1055.

16. Chen, Z. P., Xu, J. J., Zheng, H. H., Su, Y. S., Xue, J. Y., Li, J. T., "Basic mechanical properties test and stress-strain constitutive relations of recycled coarse aggregate concrete". Journal of Building Materials, 16(1), 2013, pp. 24-32. (in Chinese)
17. Sun, Y. D., Xiao, X., "Experiment research on basic mechanic property of recycled concrete with different ratio of recycled aggregate". Advanced Materials Research, 250-253, 2011, pp. 9941000 .

18. Tabsh, S. W., Abdelfatah, A. S., "Influence of recycled concrete aggregates on strength properties of concrete". Construction and Building Materials, 23(2), 2009, pp. 1163-1167.

19. Park, W. J., Noguchi, T., Shin, S. H., Oh, D. Y., "Modulus of elasticity of recycled aggregate concrete". Magazine of Concrete Research, 67(11), 2015, pp. 585-591.

20. Chen, Z. P., Ying, W. D., Chen, Y. L., Yao, K., "Mechanical properties and constitutive relationship of short age recycled coarse aggregate concrete under tri-axial compression". Journal of Building Materials, 18(6), 2015, pp. 935-940. (in Chinese)

21. Tam, V. W. Y., Kotrayothar, D., Xiao, J. Z., "Long-term deformation behaviour of recycled aggregate concrete". Construction and Building Materials, 100, 2015, pp. 262-272.

22. Dong, J. F., Wang, Q. Y., Guan, Z. W., "Material properties of basalt fibre reinforced concrete made with recycled earthquake waste". Construction and Building Materials, 130, 2017, pp. 241251.

23. Katkhuda, H., Shatarat, N., "Improving the mechanical properties of recycled concrete aggregate using chopped basalt fibers and acid treatment". Construction and Building Materials, 140, 2017, pp. 328-335.

24. Yang, J., "Study on road performance of basalt fiber recycled concrete". Highway Traffic Science and Technology (Applied Technology Version), 12(4), 2016, pp. 134-136. (in Chinese)

25. Hou, M., Dong, J. F., Yuan, S. C., Wang, Q. Y., "Analysis of mechanical properties of recycled basalt fiber recycled concrete and its axial compression short column". Journal of North China Institute of Water Conservancy and Hydroelectric Power, 34(1), 2013, pp. 41-45. (in Chinese)

26. Fan, F. L., Xu, J. Y., Bai, E. L., He, Q., "Experimental study on impact-mechanics properties of basalt fibre reinforced concrete". Advanced Materials Research, 168-170, 2011, pp. 1910-1914.

27. Alnahhal, W., Aljidda, O., "Flexural behavior of basalt fiber reinforced concrete beams with recycled concrete coarse aggregates". Construction and Building Materials, 169, 2018, pp. 165-178.

28. Meng, W. J., Liu, H. X., Liu, G. J., Kong, X. Q., Wang, X. Z., "Bond-slip constitutive relation between BFRP Bar and Basalt Fiber Recycled aggregate Concrete". KSCE Journal of Civil Engineering, 20(5), 2016, pp. 1996-2006.

29. Liu, H. X., Yang, J. W., Wang, X. Z., "Bond behavior between BFRP bar and recycled aggregate concrete reinforced with basalt fiber". Construction and Building Materials, 135, 2017, pp. 477483.

30. Xiao, J. Z., Zhang, K. J., Akbarnezhad, A., "Variability of stressstrain relationship for recycled aggregate concrete under uniaxial compression loading”. Journal of Cleaner Production, 181, 2018, pp. 753-771.

31. Suksawang, N., Wtaife, S., Alsabbagh, A., "Evaluation of elastic modulus of fiber-reinforced concrete". ACI Materials Journal, 115(2), 2018, pp. 239-249. 